\section{THE NATURE AND TREATMENT OF PUERPERAL CONVULSIONS.}

BY ARTHUR B. STEELE, ESQ.,

Lecturer on Midwifery, Liverpool Royal Infirmary School of Medicine.

AN interesting report of a fatal case of this formidable puerperal complication, published by Mr. Evans in the British MEdical Journal of May 25th, induces me to offer some brief remarks upon a subject always interesting to those engaged in midwifery practice.

I wish to observe, in limini, that the case to which I allude appears to me, from the lucid history given by Mr. Evans, to have been of such a nature-namely, accompanied with intense toxamia, from the presence of albuminuria; and that, in all probability, a fatal issue would have taken place, whatever trentment had been adopted. Therefore, the remarks which follow will not, I trust, be regarded as a criticism upon the remedial measures employed in the particular case in question, but as suggested by a desire, if possible, to throw additional light upon some of the more perplexing differences of opinion which exist among accoucheurs upon this disease and its appropriate treatment.

First-as to general depletion by bloodletting-we have the highest authority for copious venesection as an essential part of the treatment of puerperal convulsions; and of its good effects under certain circum. stances I can add my own testimony from observation. But then by others of equal repute-M. Trousseau, for example-we are forbidden to have recourse to the lancet in this affection. How can such opposite views of treatment be reconciled? The solution of the difficulty consists in a consideration of the pathology of the disease. Without going minutely into the subject, it may be sufficient to state the well-known fact, that puerperal convulsions may arise from two distinct and opposite conditions of the system - one in which excessive distension of the vessels of the brain or spinal cord, or both, produces eclampsia by compression; the other, in which, from excessive loss of blood from hamorrhage, natural or artificial, the nervous centres are drained of their blood, giving rise to convulsions from anæmia, as was first pointed out by Dr. Marshall Hall. Thus we see that bleeding in the one case is remedial, by relieving the oppressed nervous centres, and restoring the balance of the circulation; while, in the other, it only increases the evil- "the therapeutics of the disease," as tersely put by Dr. Tyler Smith, "trenching distinctly upon its pathology." (Fournal of Obstetrics, page 499.)

Such, in brief, is the principle by which we are to be guided in the matter of bleeding in this disease. My own experience induces me to believe that, notwithstanding the high authority of $\mathbf{M}$. Troussenu, cases of puerperal convulsions are sometimes met with, in which early and copious venesection is an essential element in their successful trentment. I am unable to appreciate the principle upon which local bleeding can be useful, except, possibly, to relieve the secondary effects of continued pressure upon the brain from a long continuance of the paroxysms, which would, I think, be more effectually prevented by the relief afforded in the earlier stage by reducing the quantity and force of the general circulation by venesection.

The foregoing apparently simple and conclusive statement of the question, however satisfactorily it may dispose of the difficulty in deciding when to bleed and when to stimulate, does not, unfortunately, apply to a wide range of cases, in which the state of the circulation in the nervous centres is not the main cause of the convulsions; in many of which it may be, as M. Trousseau states, the effect of eclampsia; and in others it may not cxist to such an extent as to become a subject of material consideration in the treatment.

Besides plethora, and its opposite condition, anæmia, we have other centric causes of convulsions, which may exist either with or without the first two conditions. Such are the various forms of toxæemia depending upon those agencies which interfere with the proper depuration of the blood, as constipation, and insufficient secretion from the bowels caused by mechanical pressure of the gravid uterus upon the intestines; cholamia from insufficient action of the liver, or urremia from affection of the kidneys. In addition to all these, we have the eccentric causes of convulsions, such as emotion, irritation of the uterus and the uterine passages; and, again, irritation through the medium of more distant incident excitor nerves, as irritation of the bowels, especially the lower part of the intestinal canal, from the presence of indurated fices, worms, or the severe action of purgative medicines, all of which have been known to produce convulsions. Gastric irritation, and even irritation of the mammx, caused by excessive soreness of the nipple, with mammary in. duration, have been the cause of convulsions.
The indications for treatment in these varied conditions are too obvious to require comment; and, under such circumstances, either deple. tion or stimulation, if indicated at all, can only be regarded as sub. sidiary or secondary measures. Next to bloodletting, the most vexed question is that relating to the propricty of artificial delivery. In forming a conclusion upon this point, we must still be guided by the pathological conditions present, and their relations to the convulsions a; causes. When there is reason to believe, from the absence of any other source of irritation, that the presence of the foetus in the uterus is the exciting cause of eclampsia, delivery by the speediest methol, and that least likely to add to the irritation already existing, is the manifest indication. The propriety of emptying the uterus must entirely depend upon the peculiar circumstances in each case. If the convulsions depend upon causes evidently independent of direct uterine irritation, delivery will, I believe, usually (and I speak from observation on this point) produce no impression whatever upon the course of the disease. I have frequently found the paroxysms to continue unabated for some hours after delivery has been completed.

With reference to the mode of effecting delivery, the rule must be to adopt the means least calculated to increase irritation to the uterus; and certainly I cannot but think that the forceps, on that account, should always be preferred whenerer their application is practicable. The passing up of the small blades of the forceps through the vagina (and 0 ; uteri, when necessary) is far less calculated to produce irritation of the inciclent excitor nerves of the parturient canal than the introduction of the hand and arm in the operation of turning, or the more complicated manual operations involved in craniotomy. Wherever the forceps can be applied, their use need not be, in skilful hands, more dangernus, and, in the circumstances under consideration, I believe they would be as safe, or safer, than any other method of artificial delivery.

In conclusion, I would observe that the treatment of puerperal convulsions must, like that of almost every other disease, be founded on a system of pure eclecticism. The object is, if possible, to trace the effects to their causes, and to remove those causes in the most efficient manner. I am well aware that by many the sole origin of puerperal convulsions is thought to be urremia, as the result of excess of albumen in the urine. This, no doubt, is a very frequent, perhaps the most frequent, cause; but $I$ am not convinced that it is the invarialble cause. I also know that practitioners of much ability and experience rely chiefly, if not entirely, upon chloroform as the remely -perhaps I may venturs to say the specific-for this affection. I have had no opportunity of personal observation in the treatment of puerperal convulsions by chloroform; but I can well understand that, in many case's, it must be most useful in rendering the nervous system less susceptible of the exciting causes of eclampsia; and, from the evidence we have in its favour, it is: impossible to doubt its cfficacy; nor is its judicious employment at all irreconcilable with the principles $I$ have endeavourcd to lay down as a guide to the trentment of this formidable malady.

The explanation of the apparent difficulty suggested by the author of the report from which my remarks originated-namely, that, although albuminuria exists for some time previously to the advent of labour, it is, as a rule, only when parturition sets in that convulsions occur-may, I think, be found in the fact that, for the production of eclampsia, it is necessary to have not only an exciting cause, but a special susceptibility to impression on the nervous system. This special condition appertain: more or less to the female economy during the entire period of uterogestation and throughout the puerperal state; and we occasionally meet with convulsions as a result, at various periods of pregnancy, and sometimes also after parturition. The reason why they most frequently occur during labour is, no doubt, because at that time the condition referred to acquires its greatest intensity.

Qufkett Microscopical. Club.-The second annual genera meeting was held in the library of Univcrsity College, on July 26th. Mr. Ernest Hart, president, in the chair. The report of the committce showed that the society now numbers 273 members, of whom 130 were elected during the year ; that many papers of microscopic interest had been read, field excursions successfully carried out, and class instruction in the uses of the microscope afforded to the younger members. The treasurer's report gave a satisfactory balance. The president in his address urged upon microscopists generally the great importance of making the microscope a means for scientific investigation. The following officers were elected for the ensuing year :-President, Mr. Arthur E. Durham, F.L.S.; Vice-presidents, Dr. Tilbury Fox, M.R.C.P., Mr. Ernest Hart, Mr. William Hislop, F.R.A.S., Mr. John K. Lord, F.Z.S.; Treasurci; Mr. Robert Hardwicke, F.L.S.; Hon. Secretury', Mr. Witham M. Bywater; Hon. Secritary for forcign correspondence, Mr. M. C. Cooke ; Committe, Mr. W. J. De L. Arnold, Mr. N. Burgess, Mr. S. J. M'Intire, and Mr. J. Slade. 